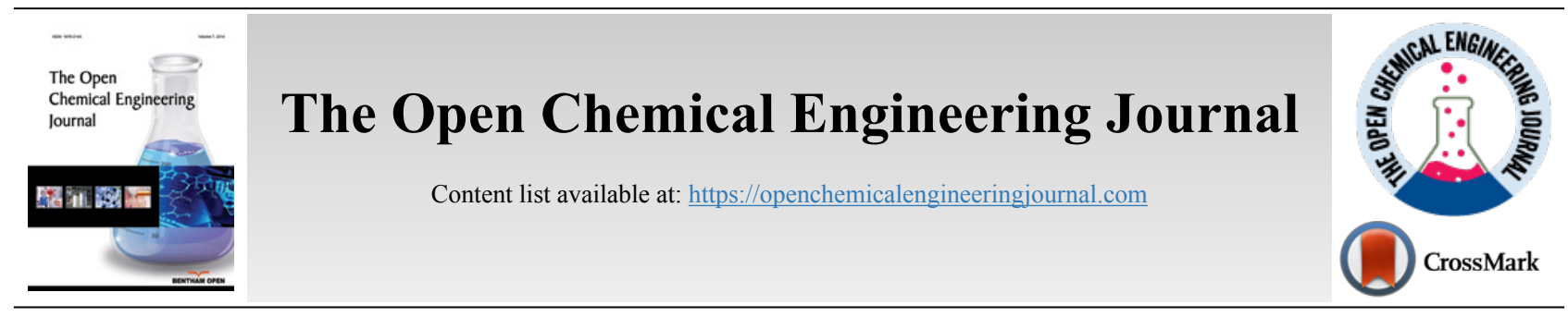

RESEARCH ARTICLE

\title{
Neutralizing Aminesin Boiler Steam and Humidified Indoor Air
}

\author{
Andrew Gomes ${ }^{1}$, Ye Tao ${ }^{1, *}$, Abdul Bhuiyan ${ }^{1}$, Don Guan $^{1}$ and Farhad Memarzadeh ${ }^{1}$ \\ ${ }^{1}$ National Institutes of Health, Division of Technical Resources, Bethesda, Maryland 20899, United States
}

\begin{abstract}
:
Objective:

The health and comfort of the indoor population have been impacted by the humidity. While people are increasingly spending more time indoors, the presence of pollutants and lack of proper humidification in indoor air have significant risk factors that may lead to multiple health problems.

Methods:

By applying the right air purification and/or humidification system, the adverse effects of poor indoor air quality can be minimized. Direct steam addition is a common technique to humidify the indoor air of a building. Carbon dioxide or other acidic process contaminants may dissolve in steam or steam condensate that will consequently decrease the $\mathrm{pH}$ and make it corrosive for the steam distribution system. To avoid that, neutralizing amines are added to steam that keeps the $\mathrm{pH}$ neutral or slightly alkaline(pH 7.5-9.0). However, neutralizing amines have some toxic effects. OSHA, FDA, and NIOSH prescribe maximum concentration limits for them in indoor air. The Central Utility Plant (CUP) of National Institutes of Health (NIH) uses a 50:50 blend of cyclohexylamine and diethylaminoethanol as neutralizing agents for the steam.
\end{abstract}

Results:

The CUP at NIH presents the results of monitoring the concentration level of amines through mass balance, online monitoring at specified location of the steam distribution system and field measurement in humidified indoor air at buildings on campus.

Conclusion

Through theoretical calculation backed up by field measurement, the amine concentration of indoor air is determined to be well below the FDA regulated limits.

Article History $\quad$ Received: September 29, 2020

Revised: February 13, 2021

Accepted: February 28, 2021

\section{INTRODUCTION}

\subsection{Humidification Methods}

Air humidity has an essential impact on health and productivity. The correct humidity level in the respiratory air prevents the mucus membrane from drying out and reduces the risk posed by microorganisms and the occurrence of specific symptoms of illness. The right amount of humidity in indoor air provides comfort to the body, improves health, and increases the durability of materials [1].

There are mainly two ways of humidifying indoor air: adiabatic and isothermal. Adiabatic humidification injects fine water droplets into the air, and the heat of the surrounding air causes the water to evaporate. There is no contribution of external thermal energy. Isothermal humidification, however,

\footnotetext{
* Address correspondence to this author at National Institutes of Health, Division of Technical Resources, Bethesda, Maryland 20899, United States; Tel: 2402054686; E-mail: ye.tao@nih.gov
}

requires an external energy source to change the state of water from liquid to vapor [2]. Direct injection of steam from a central boiler plant is commonly used in many commercial and industrial facilities as a means of isothermal humidification [3], which is also adopted by the Central Utility Plant (CUP) at the National Institutes of Health (NIH).

\subsection{Clean Steam and Utility Steam}

Steam is produced in various ways depending on the application. 'Clean' steam is used in thepharmaceutical and health care industries where sterilization iscritical. It is also needed inclean rooms in pharmaceuticalmanufacturing plants forthe manufacture of sterile compounds or ingestible medications. A secondary generator produces 'clean steam' using the heat from the central plant steam line.By using 'clean'steam, manufacturers know there willbe no boiler additives, volatiles, andparticulates that could taint, blight,or contaminate the production process. In addition, 'clean' steam 
is often used notonly to remove contaminants, but alsoto ensure the quality control of criticalattributes such as dryness, superheat,and production of non-condensablegases, all of which could adverselyaffect the process and equipment. However, it is costly to use 'clean' steam due to prior purification of water and high quality non-corrosive conduit components that are very expensive [3].

Direct steam injection is a type of humidification method which applies the utility steam produced by the central plant steam systems. A steam/condensate system issubject to corrosion due to the carbondioxide $\left(\mathrm{CO}_{2}\right)$ presence. 'Utility' steam from a conventionalboiler contains anti-corrosion chemicals (amines) that help prevent equipment failure, increase reliability, and distribution system life [3]. The amines injected in the steam usedfor humidification are carried viahumidifiers into room air, where theyare inhaled andingested via hand-to-mouth contactof surface deposits. These amines havebeen implicated, mostly based onanecdotal evidence, as the causative agents for adverse health effects such as eye, upper respiratory, and skin irritations on humans and animals. The NIH vivarium applies direct injection of steam produced by the Central Utility Plant. Therefore, it is necessary to monitor the amine concentration in the humidified air for the safety of research staff and animals.

\subsection{Source of $\mathrm{CO}_{2}$ in Steam}

When the generated steam leaves the boiler through piping to transfer heat to a heat exchanger or steam jacket, it condenses in the pipes, which tends to run to the bottom of the pipe and is carried along with the steam flow. In many industrial plants, this condensate may gather numerous impurities in the process, such as suspended solids, oil and grease, and dissolved mineral salts. A very common impurity is carbon dioxide that may produce from the breaking down of bicarbonates/carbonates in the boiler, and it can convert to the carbonic acid in the condensate and lower the condensate $\mathrm{pH}$. Typically, condensate $\mathrm{pH}$ is monitored by measuring the $\mathrm{pH}$ of the condensed steam at different locations of the steam distribution system, such as immediately after steam generation before amine injection, after amine injection, and at different other locations of the steam distribution system. The amount of $\mathrm{CO}_{2}$ that dissolves depends upon the percent of the steam that condenses and the degree of subcooling. The addition of $1 \mathrm{ppm}$ $\mathrm{CO}_{2}$ to a system of $\mathrm{pH} 7$ will change the $\mathrm{pH}$ to 5.49. If left untreated, acidic condensate corrodes condensate return piping, pipe threads, nipples, and elbows, which will eventually lead to leaks, equipment deterioration and failure [4].

\section{4. $\mathrm{CO}_{2}$ Corrosion on Steel Piping}

Carbon dioxide released into the steam due to thermal decomposition of boiler water alkalinity will eventually dissolve in the steam condensate. The dissolved $\mathrm{CO}_{2}$ in the condensate is highly corrosive and can cause significant damage to steel piping. The following reaction would occur between $\mathrm{CO}_{2}$ and condensate.

$$
\mathrm{CO}_{2}+\mathrm{H}_{2} \mathrm{O} \rightarrow \mathrm{H}_{2} \mathrm{CO}_{3}
$$

Carbonic acid would form as a product. As a result, the $\mathrm{pH}$ of condensate would be depressed. Carbonic acid would react with iron and releases hydrogen.

$$
\begin{gathered}
\mathrm{H}_{2} \mathrm{CO}_{3} \rightarrow \mathrm{H}^{+}+\mathrm{HCO}_{3}^{-} \\
\mathrm{Fe}+2 \mathrm{H}^{+}+2 \mathrm{HCO}_{3}^{-} \rightarrow \mathrm{Fe}\left(\mathrm{HCO}_{3}\right)_{2}+\mathrm{H}_{2}
\end{gathered}
$$

Consequently, metal loss would occur. The corrosion process usually happens at the bottom of the pipe, and steam traps. The corrosion is influenced by the temperature and $\mathrm{pH}$. Studies showed that the thickness of the iron corrosion product layer decreases with the increasing temperature. The corrosion product also varies in several forms, with iron carbonate as the main product followed by limited amounts of $\mathrm{Fe}_{3} \mathrm{C}$ or $\mathrm{Fe}_{3} \mathrm{O}_{4}$ at higher or lower temperature [5]. Further study showed that the corrosion rate of carbon steel is the highest at $\mathrm{pH}$ of 4.0 [6].

\subsection{Properties of Neutralizing Amines}

Condensate systems are chemically treated to reduce metal corrosion. Generally, a combination of neutralizing amines, and oxygen scavenger-metal passivators are used for this purpose.It takes one mole of amine to neutralize one mole of carbonic acid. When feeding the amine to the feed water system, it should be fed downstream of the deaerating equipment. The neutralizing amine is volatile and carried out with the steam in the condensate to react with carbon dioxide. Three factors are considered for amine blending, namely basicity (signifies by base hydrolysis constant, $\mathrm{K}_{\mathrm{b}}$ ), neutralizing capacity, and distribution ratio (DR, i.e., [concentration in vapor phase]/[concentration in liquid phase]). The greater the value of $\mathrm{K}_{\mathrm{b}}$, the more basic is the amine. The neutralizing capacity of amine is inversely proportional to the molecular weight of amine, and positively correlated to the number of amine groups in the molecule. DR indicates if an amine has a short run, medium run, or long run distribution.Low DR amines will concentrate in the condensate providing good tank protection,but its concentration will diminish as it travels down the steam line. A high DR amine will remain in the steam and travel further down the system and provide better protection at distant locations [7].

The four most common neutralizing amines are ammonia, cyclohexylamine (CHA), diethylaminoethanol (DEAE), and morpholine (MORPH). Fig. (1a-b) shows graphic comparisons of the above properties for some common amines. Fig. (1b) also includes the distribution ratio of $\mathrm{CO}_{2}$ at 10 psig and 150 psig within the $\mathrm{pH}$ range of 7.5-9.5. It provides a relative vapor/liquid $(\mathrm{V} / \mathrm{L})$ distribution ratio comparison among different amines and $\mathrm{CO}_{2}$. It also indicates that $\mathrm{CO}_{2}$ gas spreads easily throughout the steam system, forming carbonic acid almost everywhere. As the steam condenses back to its liquid phase, the high DR amines traveling further down the system also return to their aqueous phase, neutralize the $\mathrm{CO}_{2}$ in condensate and prevent corrosion [8 - 11]. 


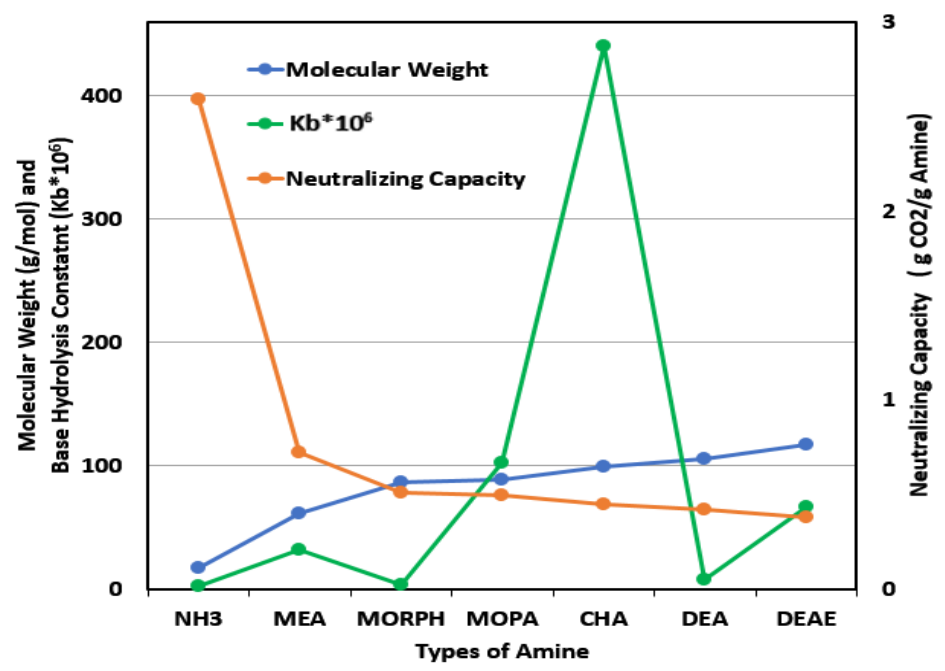

(a)

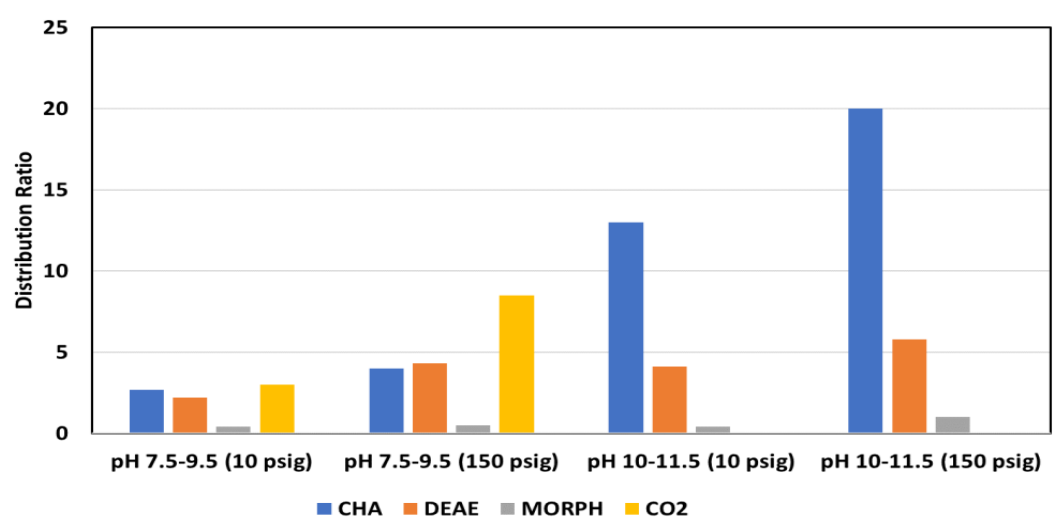

(b)

Fig. (1). (a) Graphic Comparison of molecular weight, basicity, and neutralizing capacity for $\mathrm{NH}_{3}$ (ammonia), MEA (monoethanolamine), MORPH (morpholine), MOPA (methoxypropylamine), CHA (cyclohexylamine), DEA (diethanolamine), and DEAE (diethylaminoethanol) [10]. (b) Comparison of distribution ratio at different $\mathrm{pH}$ range and pressures for cyclohexylamine, diethylaminoethanol, morpholine, and carbon dioxide [11].

\subsection{Typical Amine Control Limits}

The Code of Federal Regulations is shown in Table $\mathbf{1}$ [12 15]. The Federal Agencies regulating the amine concentration includes Food and Drug Administration (FDA), Occupational Safety and Health Administration (OSHA), American Conference of Governmental Industrial Hygienists (ACGIH), and National Institutes for Occupational Safety and Health (NIOSH). The FDA has approved MORPH,CHA, and DEAE for use in steam generation systems. The CUPfollows FDA control limits for $\operatorname{DEAE}(15 \mathrm{ppm})$ and CHA (10 ppm)under FDA 21 CFR 173.310, Title 21 CFR 184.1139 [3].

\subsection{National Institutes of Health Central Utilities PlantCyclohexylamine Inline Measurement}

The CUP of NIH currently injects a 50/50 neutralizing amine blend of CHA and DEAE. The CUP adds amines at twoseparate locations in-house at the steam distribution line after generation. The CUP has installed a neutralizing amine sensor in building 10CRC (Fig. 2) that reads specifically CHA concentration in parts per million (ppm). The Pyxis CHA analyzer is an online device that uses a reagent-based fluorescence technique to measure the CHA concentration in a steam condensate sample. The reagent reacts with $\mathrm{CHA}$ to form a fluorescent substance. The fluorescent substance formed is measured by an online fluorometer.The panel requires access to electrical service (110 VAC), cooling water, and a steam condensate sample line [16]. The CUP monitors the level of CHA after condensing the steam at building 10CRC of the steam distribution system. Fig. (2a) shows the image of the analyzer installed at one of the facility building. The analyzer takes a sample of the condensed steam and have the sample react with reagent to generate fluorescence readings. The readings are recorded by the analyzer and monitored by the engineers at the central utility plant. The analyzer dimensions and layout are shown in Fig. (2b). Fig. (2c) shows how the sample flow was controlled in the analyzer. The analyzer also has a sample port for taking steam condensate samples manually. 
Table 1. Regulatory limits prescribed by federal agencies.

\begin{tabular}{|c|c|c|c|c|c|}
\hline Neutralizing Amines & $\begin{array}{l}\text { Maximum Concentration in } \\
\text { Steam that Contacts Food } \\
\text { Products (FDA) }[12]\end{array}$ & $\begin{array}{l}\text { Max. Conc. Amine } \\
\text { in Indoor Air } \\
\text { (OSHA, PEL) }[13]\end{array}$ & $\begin{array}{l}\text { Max. Conc. Amine } \\
\text { in Indoor Air } \\
\text { (ACGIH, TLV) [14] }\end{array}$ & $\begin{array}{l}\text { TWA Exposure of } 8 \\
\text { h (Air, OSHA) [13] }\end{array}$ & $\begin{array}{c}\text { NIOSH, REL } \\
\text { (TWA) [15] }\end{array}$ \\
\hline Cyclohexylamine & $\leq 10 \mathrm{ppm}$ & - & $\leq 10 \mathrm{ppm}$ & $\leq 40 \mathrm{mg} / \mathrm{m}^{3}$ air & $\leq 10 \mathrm{ppm}$ \\
\hline Diethylaminoethanol & $\leq 15 \mathrm{ppm}$ & $\leq 10 \mathrm{ppm}$ & $\leq 2 \mathrm{ppm}$ & $\leq 50 \mathrm{mg} / \mathrm{m}^{3}$ air & $\leq 10 \mathrm{ppm}$ \\
\hline Morpholine & $\leq 10 \mathrm{ppm}$ & $\leq 20 \mathrm{ppm}$ & $\leq 10 \mathrm{ppm}$ & $\leq 70 \mathrm{mg} / \mathrm{m}^{3}$ air & $\leq 20 \mathrm{ppm}$ \\
\hline Ammonium hydroxide & No limitation in steam/not excessive & $\leq 50 \mathrm{ppm}$ & - & - & $\leq 25 \mathrm{ppm}$ \\
\hline
\end{tabular}

PEL: Permissible Exposure Limit. TLV: Threshold Limit Value; TWA: Time Weighted Average. REL: Recommended Exposure Limit.

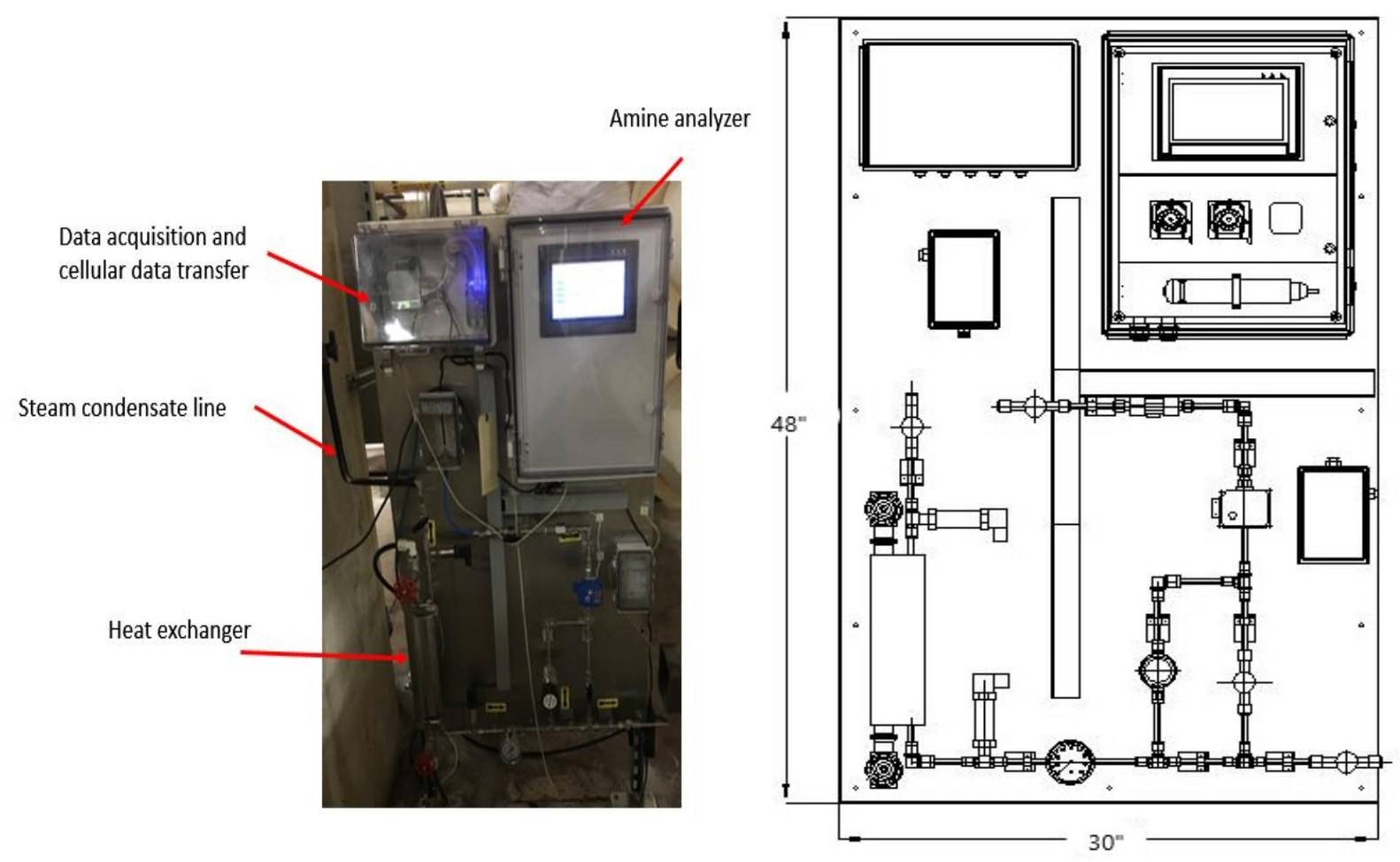

(a)

(b)

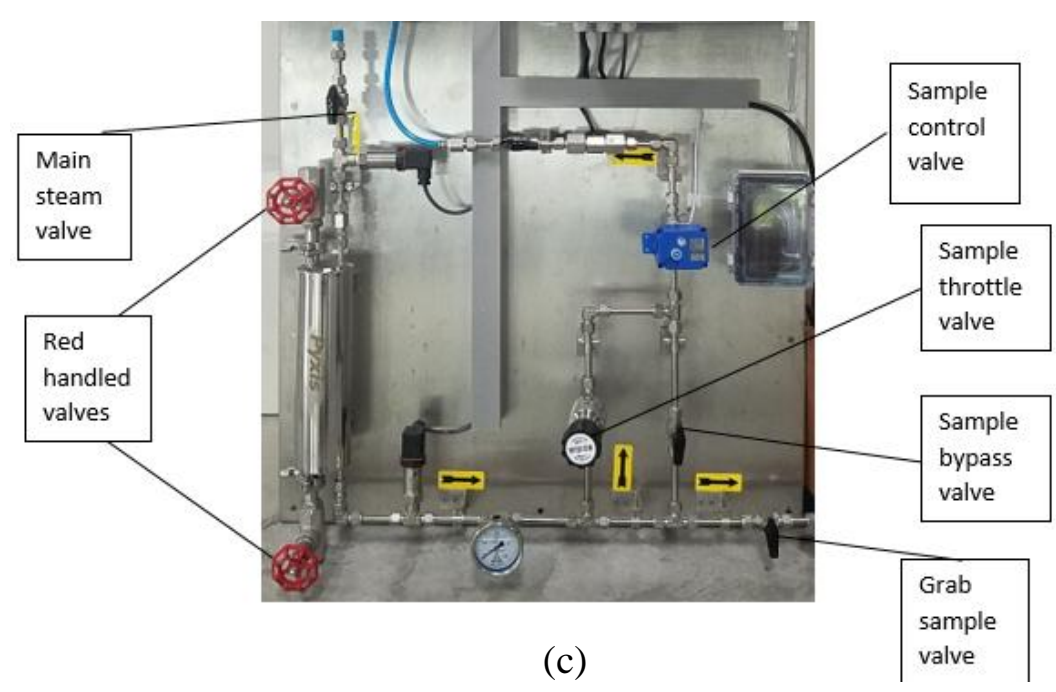

Fig. (2). (a) Image of Pyxis amine online monitoring System in building 10CRC, (b) analyzer dimensions and layout, and (c) sample panel valves. 


\subsection{Background and Objectives of the Study}

The NIH has 11 buildings encompassing 300,000 square feet of animal housing and laboratories space at the Bethesda Campus. Approximately 100,000 animals, including rodents, rabbits, primates, carnivores and ungulates are managed by the animal facility personnel on campus. Humidity control is required in all animal facilities for the well-being of laboratory animals. The direct injection of steam from a central boiler plant is the most economical humidification method. However, the health of facility personnel is a primary concern for using utility steam for humidification purposes. The focus of this study is to address the concern by measuring the concentration of CHA and DEAE and show that the concentrations of the aforementioned corrosion inhibitor chemicals are well below the FDA limit to cause any human health effects. To the best of the authors' knowledge, the study performed in this paperhas not been done elsewhere in the recent decades and would be of general interest to the scientific community.

\section{EXPERIMENTAL PROCEDURE}

To monitor the amine concentration in the indoor air, field measurements are performed. The relative humidity of the rooms measured in two different buildings on campus are listed in Table 2.

\section{Table 2. Relative humidity and temperatures in rooms where amine sampling was conducted}

\begin{tabular}{|c|c|c|c|}
\hline Building & Room Type & RH \% & Temperature $\left({ }^{\circ} \mathbf{C}\right)$ \\
\hline \multirow{3}{*}{10} & Vivarium 1 & 58 & 21.7 \\
\cline { 2 - 4 } & Vivarium 2 & 52 & 22.1 \\
\cline { 2 - 4 } & Procedure 1 & 50 & 21.6 \\
\cline { 2 - 4 } & Procedure 2 & 46 & 22.5 \\
\hline \multirow{3}{*}{ 14C } & Vivarium 1 & 54 & 24.9 \\
\cline { 2 - 4 } & Vivarium 2 & 45 & 22.0 \\
\cline { 2 - 4 } & Procedure 1 & 47 & 22.2 \\
\cline { 2 - 4 } & Procedure 2 & 52 & 21.9 \\
\hline
\end{tabular}

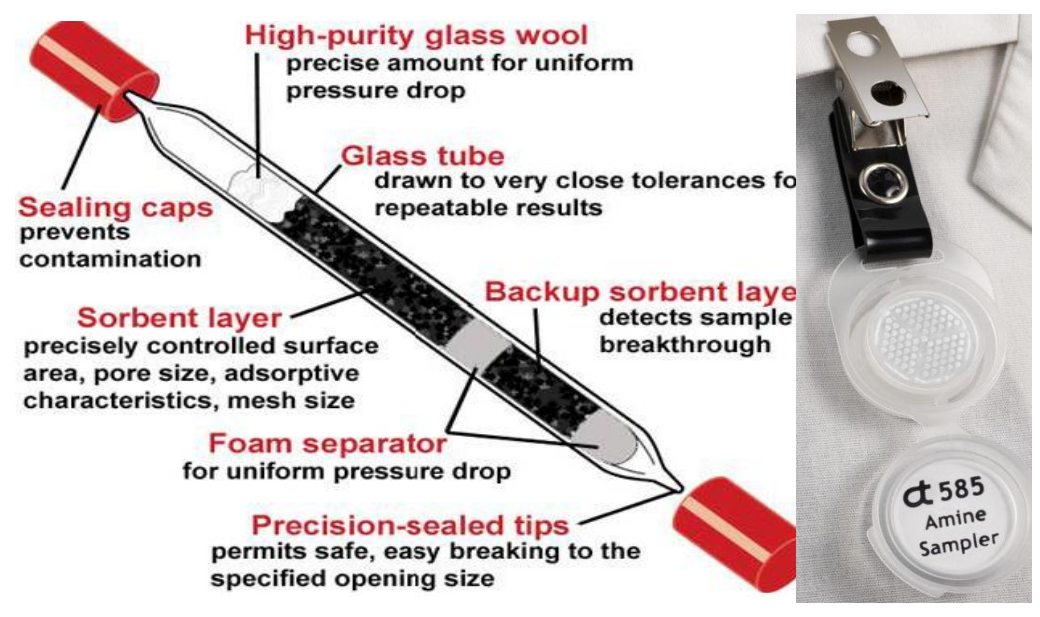

(a)

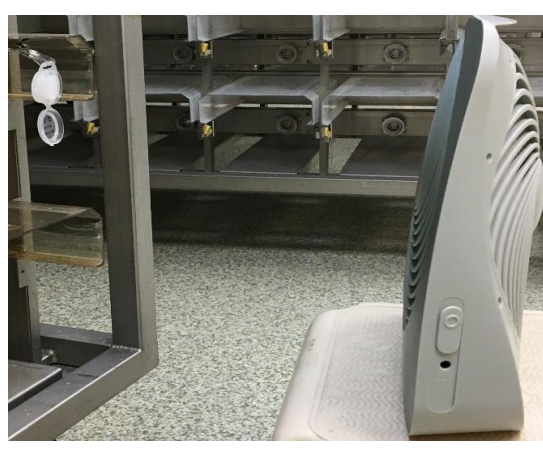

(c)

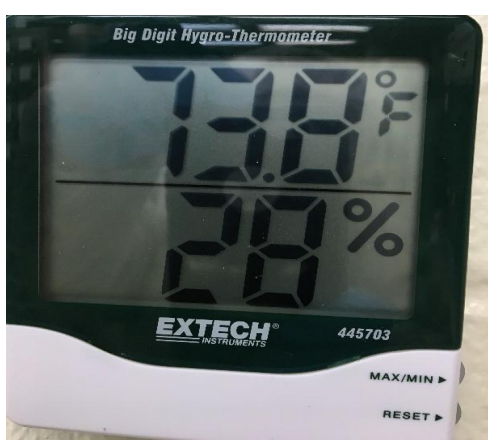

(d) (b)

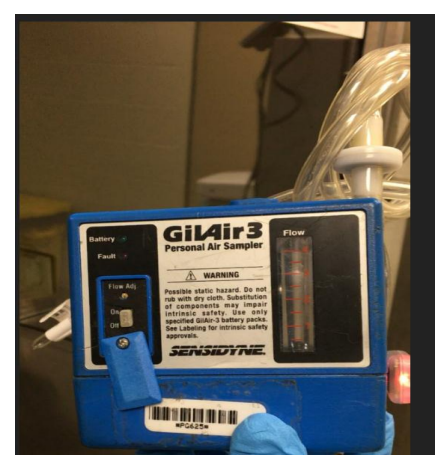

(e)

Fig. (3). (a) XAD-7 adsorption tube, (b) Diffusion Badge for collection of amines from indoor air [19, 22], (c) diffusion badge in the field with air circulating fan, (d) humidity and temperature meter, and (e) air sampler for the adsorption tube. 
Fig. (3) shows various methods that NIH adopted to measure the amine concentration. NIH measures neutralizing amine concentration at the procedure rooms and vivarium mainly by drawing a known volume of air through a $10 \%$ phosphoric acid coated XAD-7 tube (PV2016, SGS Galson)at an air flow rate of $0.1 \mathrm{~L} / \mathrm{min}$ for 4 to 8 hours [17]. The CHA adsorbed samples are sent to the certified lab. There, samples are desorbed with $1 \mathrm{~mL}$ of 1:1 solution of methanol:deionized water for $1 / 2$ hour with shaking, then $0.5 \mathrm{~mL}$ of the sample is removed and added to $0.5 \mathrm{~mL}$ of $1: 4$ solution of $1.0 \mathrm{M}$ $\mathrm{NaOHandmethanol} \mathrm{and} \mathrm{analyzed} \mathrm{by} \mathrm{gas} \mathrm{chromatography} \mathrm{using}$ a flame ionization detector (GC-FID). NIH also uses Badge technique to compare the results with higher sensitivity [18]. Samples are collected with gentle air circulationon fiberglass treated with 1-naphthyl isothiocyanate (NIT) through passive diffusion badge method at a typical sampling rate of 7-14 $\mathrm{mL} / \mathrm{min}$ for 8 hours [19]. The sample is desorbed with acetonitrile and the resulting derivatives are analyzed using an HPLC with a UV/VIS detector(OSHA 60, Assay Technology) [20].DEAE is collected by drawing a known volume of indoor air (e.g., at an air flow rate of $0.1 \mathrm{~L} / \mathrm{min}$ for 8 hours) through a silica gel sorbent tube following NIOSH 2010 method [21]. The measurement technique is gas chromatography (GC) with Nitrogen-Phosphorus Detector (NPD).

\section{RESULTS AND DISCUSSION}

The standard deviation of detected concentrations isshown in Table $\mathbf{3}$ within two significant numbers.

The inline amine monitor measures the concentration of CHA in steam distribution lines. The measured value is always verified by performing mass balance using the injected amines, steam load, and recycled amines. For example, if the weekly produced steam is 35.4 million $\mathrm{lbs}$, injected neutralizing amines (25\% CHA) $553.4 \mathrm{lbs}$, the calculated CHA concentration should be theoretically $3.9 \mathrm{ppm}$.

\section{CHA concentration in the steam}

$$
\begin{aligned}
& =\frac{\text { Weekly injected amines in lbs }}{\text { Weekly produced steam in million lbs }} \\
& * \text { mass fraction of CHA in total amines }
\end{aligned}
$$

Consideringcondensate return as $61 \%$, the estimated recycled CHA should be $2.4 \mathrm{ppm}$. Therefore, the calculated CHA should be $6.3 \mathrm{ppm}$. The inline CHA reads $6.0 \mathrm{ppm}$ that is $5 \%$ lower than the concentration calculated through mass balance.

The estimation of amine concentration in the measured room is shown as follows. To start with the mass balance (Equation 5), with illustration (Fig. 4):

$$
Q_{0} C_{0}-Q_{1} C_{1}+\int_{0}^{V} G d V=\frac{d M}{d t}
$$

[1] Where $\frac{d M}{d t}$ represents the change of mass of amine in the room.

[2] $\int_{0}^{V} G d V$ represents the generation of amine within the volume of room $\mathrm{V}$.

[3] Q represents the inlet volumetric air flow rate.

[4] $Q_{1}$ represents the outlet volumetric air flow rate.

[5] C represents the inlet concentration of amine in the air.

[6] $\mathrm{C}_{1}$ represents the outlet concentration of amine in the air.

Table 3. Field Measurement of CHA and DEAE in indoor air using active cartridge method and passive diffusion badge method.

\begin{tabular}{|c|c|c|c|}
\hline Events & May-2019 & Aug-2019 & January-2020 \\
\hline Buildings & 10 (4th Floor $)$ & $14 C$ & $14 C$ \\
\hline CHA using cartridge: OSHA PV2016: GC/FID & $<0.120 \pm 0.074 \mathrm{ppm}$ & $<0.120 \pm 0.074 \mathrm{ppm}$ & $<0.26 \pm 0.14 \mathrm{ppm}$ \\
\hline CHA using Badge: OSHA 60, HPLC/UV & - & - & $<0.0350 \pm 0.0088 \mathrm{ppm}$ \\
\hline DEAE using cartridge: NIOSH2010: GC/NPD & - & - & $<0.0087 \pm 0.0017 \mathrm{ppm}$ \\
\hline
\end{tabular}

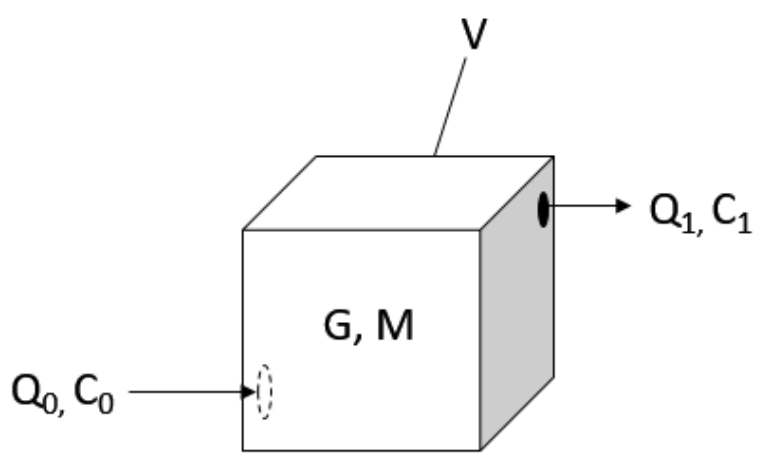

Fig. (4). Mass balance of amine in a humidified room. 
Assume steady-state condition, there is no change of mass of amine in the room, and no generation of amine inside of the room, the equation is derived to:

$$
Q_{0} C_{0}=Q_{1} C_{1}
$$

The concentration ratio determines the relationship between inlet air flow and the return air flow:

$$
\frac{Q_{0}}{Q_{1}}=\frac{C_{1}}{C_{0}}
$$

Under steady-state, the concentration of amine leaving the room should be equal to the concentration of amine inside of the room.

Taking the August, 2019 measurement of building 14C as an example, the measured CHA concentration in the room is less than $0.12 \mathrm{ppm}$ and the CHA concentration in the injected steam is $3.9 \mathrm{ppm}$. The room is under neither positive nor negative pressure, therefore $\mathrm{Q}=\mathrm{Q}_{1}$. As a result, the inlet concentration of amine in the air is equal to the outlet concentration of amine in the air. The inlet steam injection is then calculated to be $3 \%$ of the inlet airflow, which is within the controlled range of the building operation.

The relative humidity is defined based on the vapor density in the air.

$$
R H=\frac{\text { Actual vapor density }}{\text { Saturated vapor density }} \times 100 \%
$$

At $50 \%$ relative humidity and $20^{\circ} \mathrm{C}$, the saturated vapor density is at $17.3 \mathrm{~g} / \mathrm{m}^{3}$, and the actual vapor density in the air is $8.6 \mathrm{~g} / \mathrm{m}^{3}$. The room of measurement is $22 \mathrm{~m}^{3}$, the mass of water vapor in the room is calculated to be $190 \mathrm{~g}$. Assuming the water vapor is all coming from the direct injection of steam, the amine amount in the water vapor at $3.9 \mathrm{ppm}$ of concentration is $0.00074 \mathrm{~g}$. The total mass of air and moisture in the room is $27037 \mathrm{~g}$, therefore at a steady-state, the amine concentration in the room is $0.027 \mathrm{ppm}$, which is within the measured concentration limit in Table 3.

\section{CONCLUSION}

The NIH CUP is actively working on protecting the health and safety of the general public. Real-time measurement coupled with field monitoringof neutralizing amines can ensure the safety of animal facility personnel, without compromising the well-being of laboratory animals and steam distribution system integrity. The amine concentration is proven both mathematically and experimentally to be much lower than the Federal agency regulated limits. Based on the finding of this paper, the authors are confident that direct steam injection for building humidification is cost-effective and safe considering FDA and other agency permissible amine limits.

\section{CONSENT FOR PUBLICATION}

Not applicable.

\section{AVAILABILITY OF DATA AND MATERIAL}

Not applicable.

\section{FUNDING}

None.

\section{CONFLICT OF INTEREST}

The authors declare no conflict of interest, financial or otherwise.

\section{ACKNOWLEDGEMENTS}

None.

\section{REFERENCES}

[1] D.P. Kelly, W. Chen, J. Marra, C.R. Ronda, J.R. McGarva, X. Zhang, J.F. Suijver, and J-P. Jacobs, "Air humidification and/or purification", U. S. Patent 10364994B2, 2019.

[2] C. Edmondson, and N. Hall, Humidification Basics Part 2: Mastering the Terminology, JMP Study Hall, 2016.http://jmpcoblog.com/ hvacblog/humidification-basics-part-2-mastering-the-terminology

[3] F. Memarzadeh, "Adding amines to steam forhumidification", $J$. Chem. Health Saf., vol. 21, no. 4, pp. 5-17, 2014. [http://dx.doi.org/10.1016/j.jchas.2014.01.002]

[4] ChemTreat Application Notes, Steam and Condensate: Carryover of excess impurities from the boiler can cause significant downstream problems., 2020.Accessed on November $30 \mathrm{https} / / / \mathrm{www}$. chemtreat.com/applications/boiler-water-treatment/

[5] Z.F. Yin, Y.R. Feng, W.Z. Zhao, Z.Q. Bai, and G.F. Lin, "Effect of temperature on $\mathrm{CO} 2$ corrosion of carbon steel", Surf. Interface Anal., vol. 41, pp. 517-523, 2009.

[http://dx.doi.org/10.1002/sia.3057]

[6] T. Tanupabrungsun, B. Brown, and S. Nesic, "Effect of $\mathrm{pH}$ on $\mathrm{CO}_{2}$ corrosion of Mild Steel at Elevated Temperatures", NACE International Conference, 2013

[7] Handbook of Industrial Water Treatment, Condensate System Corrosion., Suez Water Technologies \& Solutions, 2020. [https://www.suezwatertechnologies.com/handbook/chapter-19-conde nsate-system-corrosion]

[8] D. A. Grattan, M. E. Koutek, and S. A. Russum, "Amine Levels in Steam-Humidified Room Air", Engineered Systems, pp. 70-74, 1989.https://www.armstronginternational.com/files/products/humidifie rs/pdf/techreports/aminelevels.pdf

[9] Taylor, Analyzing Amines.Accessed on November 30 https://taylortechnologies. com/en/page/131/analyzing-amines

[10] O. Hollander, "Condensate Treatment", inTechnical Reference and Training Manual., Association of Water Technologies, 2001.

[11] "The Nalco Water Handbook", In: Methods of Condensate Corrosion Inhibition, vol. Chapter 13. 2009.

[12] Code of Federal Regulations, Title 21, U.S. Food and Drug Administration, 2019. https://www.accessdata.fda.gov/scripts/cdrh/ cfdocs/cfcfr/CFRSearch.cfm?FR=173.310

[13] Occupational Safety and Health Administration, Permissible Exposure Limits -Annotated Tables, U.S. Department of Labor., 2020.Accessed on November 30. 2020.

[14] American Conference of Governmental Industrial Hygienists, Chemical Data Base, 2020. https://www.acgih.org/forms/store/ ProductFormPublic/search?action=1

[15] The National Institute for Occupational Safety and Health (NIOSH), NIOSH Data Base, 2019. https://www.cdc.gov/niosh/npg/ npgd0437.html

[16] Caibin Xiao, "Personal Communication", Pyxis Lab Inc..https://pyxis-lab.com/

[17] M. E. Eide, "Occupational Safety and Health Administration", Cyclohexylamine, Method PV2016, February 1994. https://www.osha.gov/dts/sltc/ methods/partial/pv2016/2016.html

[18] K. P. Williams, S. L. Rose-Pehrsson, and D. A. Kidwell, Passive Badge Assessment for Long-term, Low-level Air Monitoring on Submarines: Monoethanolamine Badge Validation, Naval Research Laboratory, NRL/MR/6100--05-8922, 2005. https://apps.dtic.mil/ dtic/tr/fulltext/u2/a440165.pdf

[19] Assay Technology, 585 Organic Amines Monitor, 2020. https://www.assaytech.com/product/585-organic-amines-monitor/

[20] C. J. Elskamp, MethodOSHA 60, Occupational Safety and Health Administration, 1986. https://www.osha.gov/dts/sltc/methods/organic/ org060/org060.html 
[21] P. F. O'Connor, Revised by, aliphatic amines, Method NIOSH 2010, Manual of AnalyticalMethods (NMAM), August 15, 1994.http://ssu.ac.ir/cms/fileadmin/user_upload/Moavenatha/MBehdas hti/behdasht_herfaie/niosh_methods-a/2010.pdf

22] Air Sampling Solutions and Expertise, Sorbent Tubes, XAD-7 (phosphoric acid)SKC., .Accessed on November 30, 2020. https://www.skcinc.com/catalog/product_info.php?products_id=733

\section{2021 Gomes et al.}

This is an open access article distributed under the terms of the Creative Commons Attribution 4.0 International Public License (CC-BY 4.0), a copy of which is available at: https://creativecommons.org/licenses/by/4.0/legalcode. This license permits unrestricted use, distribution, and reproduction in any medium, provided the original author and source are credited. 